\title{
A survey for otters in
Israel
}

S.M. Macdonald, C.F. Mason and B. Shalmon

The results of a field survey for otters in Israel suggest that the species is close to extinction in the coastal plain, where many rivers are grossly polluted. Signs of the animal were found throughout the Jordan catchment, but, because the total area occupied is very small, even this population seems vulnerable.

Since otter Lutra lutra populations have declined sharply over much of western Europe, recent attempts have been made to detect remaining viable populations within the rest of the species's range. Conservation efforts could be more usefully employed in regions where healthy numbers of animals remain than in those countries where the otter is close to extinction. It is now known, for example, that the otter still thrives in Portugal, Greece and north Tunisia (see review in Mason and Macdonald, 1986), but until now very little information was available on its distribution in the Middle East.

In Israel, a survey based on reports of dead otters or sightings up to 1976 (Ilani, 1976) and a brief field survey in 1985 (Shalmon, 1986) indicated that the species was still present, but within a limited area. It seemed important, therefore, to delimit more precisely the distribution of the otter in the country and to try to determine any threats to its future survival.

\section{The survey}

The area surveyed covered most of the permanent waterways in Israel, comprising the coastal plain and the River Jordan catchment including the Hula Valley in the north and the streams running into Lake Kinneret (Sea of Galilee). The lower Jordan could not be surveyed Survey for otters in Israel for security reasons as it forms the border between Israel and Jordan. The study was carried out between 20 and 31 March, 1986.

Survey sites included rivers, irrigation channels, fish ponds and reservoirs, and at each site a search was made for otter faeces (spraints) and footprints. A site was considered negative for otters if no signs were found after a minimum search of $600 \mathrm{~m}$. At each site note was made of the habitat in terms of cover for otters, of the surrounding agriculture, visible water pollution and human disturbance. These methods have been used frequently on previous field surveys for otters (e.g. Macdonald and Mason, 1982, 1983, 1984).

\section{Results of the survey}

During the survey 95 sites were visited (see Figure 1). Of these, 19 were in the coastal plain or on rivers flowing towards the Mediterranean. Only one site, near Akko (Acre), was found to be positive. The remaining 76 sites were located within the Jordan catchment and at 60 of these (79 per cent) signs of otters were found. Throughout the survey 15 sites were at fish ponds, and evidence of otters was found at 11 of these.

Many of the rivers flowing into the Mediterranean are grossly polluted and without fish. There was visible pollution at nine of the 19 sites. At the one positive site spraints were found on the black and grossly polluted River Na'aman, but this site is close to two natural springs, one comprising the small nature reserve at Afeq.

Within the coastal region, nine of the sites visited 233 
appeared to be unsuitable for otters either because the length of running water was too short (only $1-3 \mathrm{~km}$ ) or because they comprised small reservoirs isolated in agricultural plains, unconnected to other waterways and devoid of bankside cover.

By contrast, the Jordan catchment, including the Hula Valley and Lake Kinneret, forms a continuum of waterways. There is also less water pollution. Only four of the 76 sites were grossly polluted, while slight organic pollution affected 14. The waters at the remaining 58 sites appeared to be clean.

In some upland streams, otters can find shelter amongst rocks and in the maquis. In the lowlands the major forms of cover were bramble Rubus sanctus, giant reed Arundo donax and common reed Phragmites australis, these being recorded as of importance at 58 of the 95 sites visited.

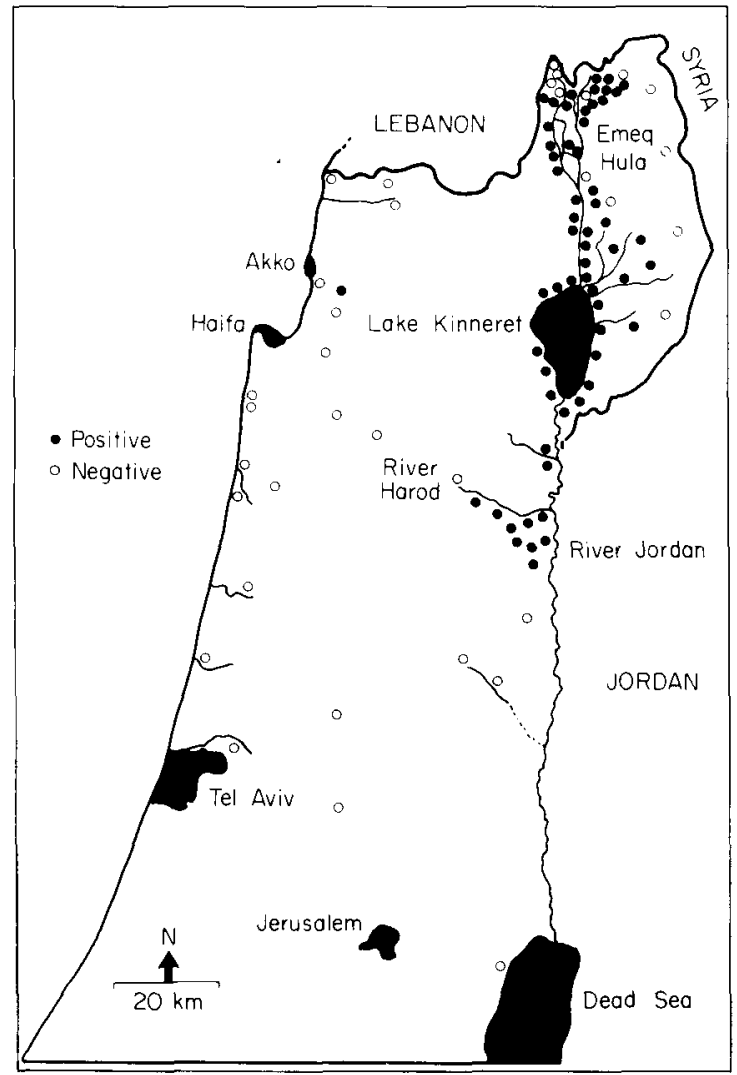

Figure 1. The study area in Israel showing sites visited.
Shelter was also provided by oleander Nerium oleander, tamarisk Tamarix and willow Salix scrub.

The level of marking by otters (for example, at one site on the Jordan 36 spraints at seven sprainting sites were recorded in $200 \mathrm{~m}$ ) and the ease with which spraints were found (at 60 per cent of positive sites spraints were found immediately and no further search was required) suggested that the otter population was thriving on the Jordan system. The animals were also, as is typical of good populations, using most available habitats. Signs were found in ditches less than $1 \mathrm{~m}$ wide and on concrete irrigation channels. Spraints were recorded at Nir David, a reserve in the River Harod catchment comprising ornamental gardens and pools crowded with daytrippers. There were spraints on the quay at Tiberias, a tourist centre on the western shore of Lake Kinneret. However, it must be stressed that the total geographic range of otters in Israel is very small (see Figure 1).

\section{Discussion and conservation}

According to information collected about otter distribution between 1863 and 1970, the animal was present in the coastal plain from Tel Aviv to the border with Lebanon and throughout the Jordan system to the Dead Sea. Records collected between 1970 and 1976 (Ilani, 1976) suggested that, within the coastal plain, the only population occurred near Akko. In the present field survey only one positive site was found near Akko and no other signs were located in the coastal plain. Gross water pollution is a major problem in the rivers of this region, while some streams only flow for very short distances, a feature exacerbated by the removal of water for irrigation. Small isolated stretches of running water cannot support populations of an animal that eats around $1 \mathrm{~kg}$ of fish a day and which may have a home range of up to $40 \mathrm{~km}$ (Green et al., 1984).

The effects of water pollution are difficult to estimate since some pollutants such as pesticides and PCBs cannot be assessed without chemical analyses. The organochlorine pesticide dieldrin was implicated in the decline of otters in Britain (Chanin and Jefferies, 1978), and PCBs have 


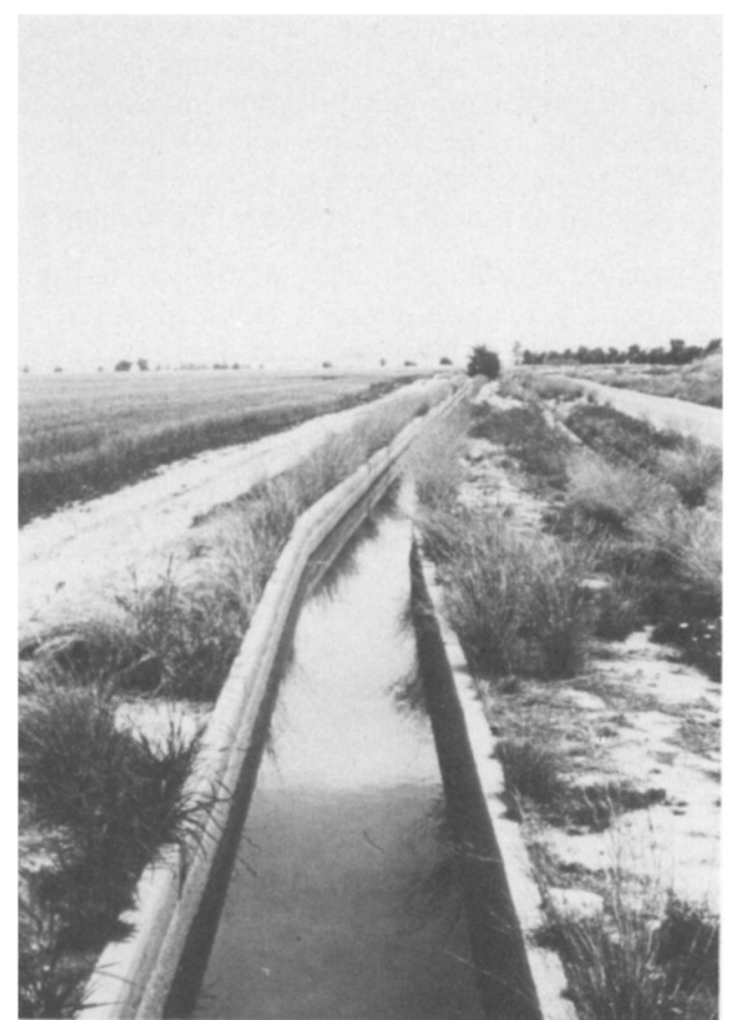

been pin-pointed as a cause for concern in Sweden (Olsson et al., 1981). Metals, for example mercury, cadmium and lead, have also been recorded in fish in Britain and may contaminate otters through the food chain (Mason et al., 1982). In the coastal plain of Israel waters are visibly contaminated with organic wastes, but are also certainly polluted with bio-accumulating agricultural chemicals. Agriculture is intensive, with cereals, fruit, vegetables and cotton being produced. The present condition of these rivers precludes any chance of otters recolonizing this area.

Otters are, however, common in the Jordan catchment, including the Hula Valley, the streams flowing into Lake Kinneret and the shores of Kinneret itself. While we were unable to survey the lower Jordan, it seems likely that otter

Left: A concrete imigation channel in the valley of the River Harod. The channel contains many fish and is heavily marked by otters. Such channels may provide routes between fish ponds and offer a food supply in regions, as here, where the main river is grossly polluted.

Below: A typical Israeli fish pond.

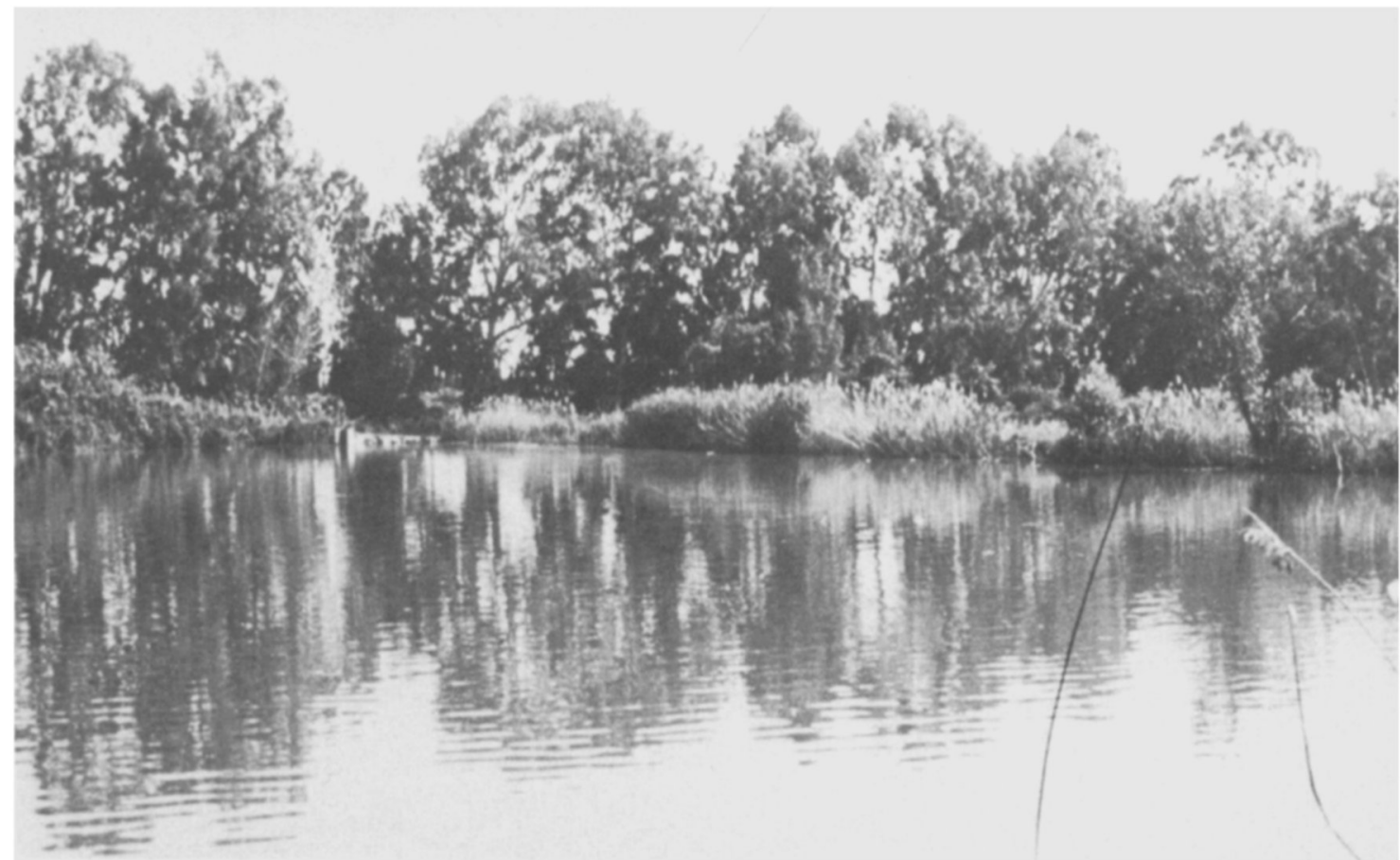


distribution extends to the Dead Sea. Throughout much of the Jordan catchment there was little visible water pollution. While the valleys are cultivated, clean waters enter the system from the uncultivable uplands. Yet, here too, some rivers are grossly polluted, for example much of the River Harod, and it may be that some otters are largely dependent on neighbouring fish ponds for their food supplies.

It is worth noting that, during the winters of 1975/. 76 and $1976 / 77$, spraying with the organophosphorus pesticide Azodrin to control voles Microtus guentheri in the Hula Valley ( $\mathrm{a}$ use not recommended by the manufacturers) caused mass mortalities of birds of prey by secondary poisoning (Mendelssohn and Paz, 1977), and the compound was found unchanged in water systems up to eight weeks after use. However, D. Wynne (in litt.) considered, from his analyses of water and fish from the catchment over the period 1980-84, that the threat to Kinneret from pesticide residues was low. Despite this, any increase in the extent of polluted waters should be avoided.

In much of western Europe, for example in Britain and Italy (Mason and Macdonald, 1986), the otters' habitat is destroyed or reduced by river managers and by farmers. In Israel, apart from some stretches of the River Jordan, there was little evidence to suggest that bankside vegetation was being destroyed; indeed, on many streams the density of riparian vegetation was impenetrable. Such vegetation provides ample shelter for otters and, physically, reduces human disturbance. However, while the present situation appears ideal, complacency should be avoided. It is important to the continued survival of the otter that the cover along waterways remains in its present form, and that Rubus, Arundo and Phragmites should be retained.

The current situation of the otter in Israel is encouraging, but it must be emphasized that the area occupied by the species is very small. Almost the entire population exists on one river catchment. This means that, while the population may be thriving at present, it is extremely vulnerable. An increase in pollutants in the waters of the Jordan could, for example, prejudice the survival of the species in Israel. Similarly, the quality of 236 water entering from Syria and Lebanon could affect the Israeli population. If efforts could be made to improve greatly the water quality in the coastal plain, it would be possible for the animal to increase its geographic range in Israel, and this would help to reduce its present vulnerability.

We would also recommend that the otters' distribution be monitored regularly so that any trend of decline may be quickly recognized. Fish from the Jordan system should be analysed routinely for organochlorines and metals. Levels of pesticides in the water itself may be low, but the concentration effects of bio-accumulation in fish can result in high levels of pollutants in otters.

\section{Acknowledgments}

We are grateful to the staff of the Field Schools of Ma'agan Mickhael, Hermon, Qazrin and En Gedi for their hospitality and interest, and to those rangers of the Nature Reserve Authority who accompanied us in the field. The survey was funded by World Wildlife Fund International, with further assistance provided by Keren Hazevi (SPNI).

\section{References}

Chanin, P.R.F. and Jefferies, D.J. 1978. The decline of the otter Lutra lutra L. in Britain: an analysis of hunting records and discussion of causes. Biol. J. Linn. Soc. 10, 305-328.

Green, J., Green, R. and Jefferies, D.J. 1984. A radio-tracking survey of otters Lutra lutra on a Perthshire river system. Lutra, 27, 85-145.

Ilani, G. 1976. Zoogeographical and ecological survey of carnivores (Mammalia: Camivora) in Israel and the administered areas. Nature Reserves Authority, Israel (in Hebrew).

Macdonald, S.M. and Mason, C.F. 1982. The otter Lutra lutra in central Portugal. Biol. Conserv. 22, 207-215.

Macdonald, S.M. and Mason, C.F. 1983. The otter Lutra lutra in southern Italy. Biol. Conserv. 25, 95-101.

Macdonald, S.M. and Mason, C.F. 1984. Otters in Morocco. Oryx, XVIII, 157-159.

Mason, C.F. and Macdonald, S.M. 1986. Otters: Ecology and Conservation. Cambridge University Press, Cambridge.

Mason, C.F., Macdonald, S.M. and Aspden, V. 1982. Metals in Freshwater Fish in the United Kingdom, 1980-1981. Vincent Wildlife Trust, London.

Mendelssohn, H. and Paz, U. 1977. Mass mortality of birds of prey caused by Azodrin, an organophosphorus insecticide. Biol. Conserv. 11, 163-170.

Olsson, M., Reutergardh, L. and Sandegren, F. 1981. Var ar uttern? Sueriges Natur, 6/8, 234-240.

Shalmon, B. 1986. Otters condition in Israel: an initial survey. Reem, 5, 41-44 (in Hebrew).

S. M. Macdonald and C. F. Mason, Department of Biology. University of Essex, Wivenhoe Park, Colchester, Essex CO4 3SQ, U.K.

B. Shalmon. Israel Mammal Information Centre. Field School, POB 204, Eilat, Israel.

Oryx Vol 20 No 4, October 1986 